\title{
Perceptions of Educational Managers on the Effectiveness of Selected Training Programmes: A Case Study in the Ministry of Education, Oman
}

\section{Aisha Salim Juma Alaraimi*, Azam Othman**}

\begin{abstract}
The present study evaluated the characteristics and effectiveness of selected training programmes for educational manager in the MoE in the Sultanate of Oman. The study investigated the effectiveness of training programmes for educational managers. Nine (9) participants were specifically selected for interview using the snowball sampling technique. The findings showed that human resource development (HRD) is undertaking intensive efforts in distributing training culture among MoE staff, $78 \%$ of the interviewers were not satisfied with training approaches and methods adopted by the trainers. Furthermore, the findings revealed that trainees were satisfied with the suitability and adequateness of training techniques, training aids and training resources. Among the findings study contributed to the body of knowledge by generating frameworks useful for measuring the characteristics and effectiveness of training programme and competence levels of educational managers. It is recommended that the MoE should ensure upgrading and extending of the existing training infrastructure at the ministry and also consider prospective trainers to a training programme. This study is likely to be of interest to those stakeholders dealing with training in education, not only in the MoE but in other institutions where training of managers are vital.
\end{abstract}

\footnotetext{
* Ministry of Education, The Sultanate Of Oman, Email: prettymum1@hotmail.com

** Assoc Prof. Kulliyyah of Education. International Islamic University Malaysia, Email: azam_othman@iium.edu.my
} 


\section{INTRODUCTION}

While many governments have become aware of the need for continuous training and development of educational leaders, even increasing the budgets allocated for that purpose, there is a dearth of concrete outcomes. Increased inputs have not been paralleled with improvement in the technical performance among staff in Ministries of Education. This is especially so in the case of the Sultanate of Oman (Al-Rawas, 2011).

The effectiveness of strategies often employed in training employees in the MoE of the Sultanate of Oman has been questioned by scholars and researchers. For instance, the training programmes for administrative staff in the Sultanate of Oman have been found lacking of proper needs analysis (Al-Qasimi, 2004; Al-Kaabi, 2002), particulary they do not employ scientific methods in conducting needs analysis and training (Sangoor, 1997; Shayban, 1993; Al-Qasimi, 2004). In addition, among some training programmes, it is observed that the needs analysis does not match with the programmes they are targeted to meet (Al-Qasimi, 2004). Another critical concern of the current training programme is its inadequacy to cater for the essential needs of the educational managers (Al-Mashekee, 2009). This deficiency has brought about repetition of some training programmes for the educational managers in the Ministry. In addition, the planning phase of training programmes is mostly done in isolation from the design and implementation of training programme. More often than not, the programmes are not structured or aligned to help the managers achieve consistence in their professional development. This makes it difficult for the training programmes to meet the needs of the educational managers.

\section{Models of effectiveness of training programmes}

Several models have been used to explain effectiveness training; the most popular being Kirkpatrick's model commonly used to study the effectiveness of performance (Kirkpatrick and Kirkpatrick, 2007). According to this model, (Kirkpatrick 1950; Croes, 2012), in evaluation of performance there are four levels of which each stage is a prerequisite or foundation of the other. The levels include:

Reaction level: This level measures trainees' reaction toward the training programme. It gives the information whether the trainees like 
the programme or not. It measures degree of trainee satisfaction towards the training programme. Many tools help to assist at this level such as; programme evaluation sheet, interview, questionnaires, survey, focus group, and immediate response and the trainee would comment throughout the training programme. The obtained information can help the trainers to improve the aims, objectives, content and training approaches of their future training programmes (Boverie et al., 1994).

Learning level: This measures the trainee knowledge that has been gained from the training programme. It assists to know the degree of the knowledge participants get from the programme, change in skills, and their behaviour. It can also assist in pre- and post- examination of the trainees after the training programme to measure the extent of learning or knowledge gained group discussion or interview. The test should relate and reflect to the learning objectives; in this case it can help to improve training approaches in addition to measuring the training programme objectives that have been achieved (Boverie et al. ,1994). At the learning level, there is a measure of the progress, attitudes, and skills of the trainees. In addition, the feedback from pre and post tests, observations, colleagues and managers help to measure the progress of this or next training programme (Croes, 2012).

Behaviour level: This measures the practices of knowledge and skills gained from the training programme at their work places. In this level, evaluation of the effectiveness training programmes tries to identify the trainees' reflections and application of skills, attitudes, and the knowledge gained from training programmes in their work. This level assesses the change in behaviour of the employees who undertook the training programmes. This level can assess by direct observation from the managers or interviews with the trainee colleagues, and from pre and post skills of the trainees who undertook the training programme. To insure the successfulness to this step, Boverie et al. (1994) advised the trainers to apply the following steps; (1) prepare a plan and to describe how the knowledge can be transferred to the working environment, and (2) organization should prepare support to transfer knowledge. Also, (3) organisation should prepare training topics, activities and the objectives needed to be related to work, (4) rewards for the desired achievement, (5) and also, to give time to measure the transfer of knowledge in utmost three to six months. The tools that help to assist in measuring this level are pre and post-tests, interview, management, and peer observation. 
Results level: It measures the benefits of the training programmes from application of the knowledge gained during training. Evaluation of the effectiveness of the training programmes can measure the success of the training programmes through the information that the managers provide, for instance, decrease costs, quality development, and increase the profits. The value of the training programme cannot be measured only from one-step, but it should be through collecting evidences from the four steps. Then, writing and presenting the final report to the decision makers, as much as the job on each level has been done well and accurate the final report will be precise and provides all the stockholders with real data (Kirkpatrick and Kirkpatrick, 2007). At the result level, there is also the measurement of the training programmes. Measurement of the value and effectiveness of training are very important in the training programmes. The organizations spend large amount of money in training. Organisations and government departments need to get more benefits from the new knowledge and skills gained from training programmes which their employees do attend.

According to D. Kirkpatrick and J. Kirkpatrick (2007) to make training programme effective there is need for certain criteria which have to be met like the rational of the programme, the adjectives, programme schedule, right trainees, match trainee need and good choice of training approaches whether be from the same organization or by adopting.

Guskey (2000) developed a model for evaluation which he adopted from Kirkpatrick (1959) which is commonly used in business and industry. The Guskey model of evaluation consisted of five stage which were distributed hierarchically, one stage leading to the other. The five levels of Guskey model are- Trainee Reactions, Trainee Learning, Organization Support and Change, Trainee Use of New Knowledge and Skills, and Trainee Learning Outcomes. These are;

$i$. Trainees' Reaction: This considers the satisfaction of the participants with the; aims, method, content, environment, facilities, time and the trainer used in the training programmes.

ii. Trainees' Learning: It examines the knowledge, beliefs, and competencies the participants gained from training activities. The trainees can be examined on knowledge and skills they have taken and can be applied. These can show, explain, and 
write proposals on how to solve specific problems. It can be either written or oral, pre- exam and post- exam. Also, the learning stage can be examined by using certain standards.

iii. Organization Support and Change: The most important element in this stage is organization. If the trainees attained a specific programme and try to practise, whatever they learned in the positive environment well, it encourages and motivates them through different way such as; let them ask to apply what they learn or train the other staff, provide them with time and resources, generalize the new knowledge and skills and reward them. In this level the success that has been attained in stage one and two, if not well nurtured, can be lost if the organization does not support well the training programmes (Guskey, 2000). Also the environment can affect the training programme but if the managers encourage the implementation of training skill and knowledge, it can be helpful in transferring of the training knowledge. Some of the components of training that can be affected in the learning transformation are training design, participants features, training content the chance to practices the training (transfer system) (Holton et al., 2000).

iv. Trainees' use of New Knowledge and Skills: The examiners in this stage will try to understand if the trainees used their new knowledge and skills, whether their methods of doing the duties are changed, and whether the change is positive or negative. To check the achievement of this level, the experts or the trainers can interview the managers of the trainees or use written or practical exam. According to Guskey (2000), the evaluation of this level should be at least three months after attending the training programme.

v. Trainees' Learning Outcomes: At this stage, participants show what they have benefited from the training activities; the general outcomes of the training on the trainees who attended the training programme. Various measurements in this stage are important for example performance, achievement, and behaviour (Guskey, 2000). The researches reports contradicted results towered the relationship between transfer system components and achievements (Holton et al., 2000). 
To put these two models in an ecological context, we can safely argue that for us to know the effectiveness of a given training program, we have to examine the inputs (in terms of the objectives, trainer characteristics, equipment and training setting) and outcomes of the training, both short-term and long-term.

\section{THE PRESENT STUDY}

Although many studies have been done on training needs analysis and development of training programmes in general (Shayban, 1993; AlAlawi, 2003; Al-Qasimi, 2004), little or no scholastic attention is given to participants' perceptions about and evaluation of the effectiveness of training programmes for educational leaders in Oman. Therefore, the ultimate concern of this qualitative study is to identify the perceptions of selected Omani educational leaders about training programmes and their evaluation of the effectiveness of such programs. This is an important first step in helping us to understand the strengths and weaknesses of training programmes and formulate an appropriate blueprint that will address both peculiar and general challenges faced by educational managers in Oman and other developing countries. The study specifically sought to answer the following question: how effective are the training programmes for educational managers in the Ministry of Education, Sultanate of Oman?

\section{METHOD}

The qualitative approach of case study was employed in this study to get a comprehensive in-depth view of the issues (Creswell, 2007). In-depth interviews were conducted with nine respondents. Respondents included three educational managers in the Omani Ministry of Education; three Omani leadership trainers working in the MoE; and two international leadership trainers. This was hoped to give us the perspectives of both the trainers and the trainees. The trainers selected for the study were based on their experience of training educational managers while the educational managers had at least five years' experience and had attended at least one training programme in the Ministry of Education. To get a complete picture of the effectiveness of training programs, four subordinates of the selected educational managers were also interviewed. In all, participants ranged in experience between 17 and 34 years. Interviews were audio-recorded and transcribed verbatim. 
Thematic analysis was then conducted following the guidelines given by Creswell (2007).

\section{RESULTS}

To answer the question of the effectiveness of training programmes for educational leaders in the Omani Ministry of Education, thematic analysis of the verbatim data collected from interviews with respondents yielded six major themes. These are: the objectives of the training program and how those objectives are formulated; trainee selection, prior knowledge, and general characteristics; contents or subject matter of training; training setting, trainer qualities, and the methods, tools and techniques used; outcomes of training in terms of changed characteristics and improved performance; and finally, mechanisms in place for evaluation and general impressions of the effectiveness of training programmes. Below is a summary of the results.

\section{Objectives of training Programmes}

The main element in any training program are its objectives. Effectiveness basically means that the program meets the objectives it was set to achieve. Thus a study of effectiveness has to start with ascertaining the suitability of the objectives. Regarding this point, many of the respondents were of the view that sometimes the objectives are not suitable for the target group. One of the respondents commented that:

"No, the Programme management and technical skills....
because it was Basic... For the second programme ... was
expressing a real technical need exists in the department
...(DU40\&44). She explained his answered by more
elaboration; "Was suitable for me if it was 3 years ago ...
or 4 years ago in my beginnings as head of department ...
has an effect .... to correct the path of the work flow in the
department".

It can be revealed from her answer that the first programme is not suitable because it contains the $\mathrm{ABCs}$ of management and she works as deputy director for more than seven years and the programme was dealt with the basic skills for educational manger. In addition, this programme was not based according to her need. The second programme was suitable for contribution to correct workflow. Informant (R3) response was close 
to $\mathrm{R} 1$ the programme as he atended for no specialized training. From his point of veiw training path is not tied to career path at $\mathrm{MoE}$ and most of MoE employees attending training programmes according to their job title are not based on real need. He said:

"Issues ... of forming team work-is not only related to job but also linked to the General Life ... it is .. not specialized ... in the Ministry we are still late because there is no clear path for each employee.... in the Ministry of Education moving to another state ...is not well planned (DU46)." He explained his answer with; At the level of the ministry I think it does not exist ... because... Now, what exist is that you are within the environment.. of human resource development programmes, so all programs you will attend will be related to the development of human resources ......"

According to a study conducted in the Ministry of Awqaf and Religious Affairs by (Al-Qasimi,2004), it was found that $89 \%$ of the sample studied lack the real need analysis of the trainees and the programmes were not related to their real task which leads to failure of the training. In a similar study conducted by Shayban (1995) it covered the civil ministries in the Sultanate that showed that most of the training plan among civil ministries rely on short-term training plan (67.9\%) and the proportion of the midterm training plan averaged (32.2\%) and longterm training plan was very limited (3.6\%).

\section{Trainee Characteristics and Prior knowledge and skills}

To ascertain the suitability of objectives, it is important to ensure that the right staff are chosen to participate in the programme. This is related to the issue of whether they have appropriate prior knowledge and experience. Regarding the method used to select trainees, we explored whether it was based on their need, if the programmes were required for the informants or their head nomination or based on job analysis and so forth. This would show the researcher if there was real need for the programme. One of the informants (R1) said:

"They wanted to cover the largest possible number of these segments of the administrative that did not receive enough training.. .. Regardless of our actual need.. ..(DU32)"

He emphasized that the training was not built on real need, it was simply intended to maximize the number of trainees. The programme 
included all administrative segments. Informants (R2) responded not far from (R1). According to her the first programme was for all recently designated as heads of section and the second programme was by nomination. Even informants (R3), from his point of view, pointed that they were nominated according to the job title. Informants (R2 \& R3) responded as follow respectively:

"Administrative and technical skills Program.. is group selection for all recently designated as heads of departments ... The second program the art of leadership was I nominations from the Department of Human Resources Development(DU40).... Just on job title... (DU40). He elaborated his answered with "been targeted managers and deputy general managers

This could reflect that there were no requirements of this type of programmes. $100 \%$ of the trainees in qualitative sample data showed that they were nominated to attend the training programme based on their job title. Identification of training needs in government institutions faces many problems, including instability of the foundations of identification of training needs (Shayban, 1995), inaccuracy of these needs with the lack of an objective method used (Al-Khabouri, 1993, Shayban, 1995; Al- Hanashi, 2004 and AL-Qasimi, 2004, Al-Hassani, 2012 ), non-participation of the trainees to identify their training needs and not to pose their views about their desires and their actual needs for training programmes and subjects (Al Qassimi, 2004).

Regarding the levels and prior knowledge of trainees, we wanted to know if the trainees had the same job title and so she might facing the same difficulties under the conditions that they had equal qualifications and experience, as for as possible to help in the detection of whether they needed the same programme or not. Approximately similar answer with further addition and elaboration were obtained from some informants that varied with background with different experiences and qualifications with similar job title. This led to mixed levels of achievement. The first informants (R1) respondents;

"Different levels of expertise......... Old and recent experience.. graduates Bachelor and Master degree .. and there are some with considerable technical expertise and that of a few expertise(DU20). She added more explanation;" 
The non-homogeneous experience..Influenced positively the program"

In her point of view, various experience and qualification helped in the enrichment of training programme. The forth informant (R4) said:

“... varies according to academic qualification, all trainees are graduated...In general, academic qualifications are homogeneous between bachelors and master's degrees ... the occupations reasonably homogeneity..... No strong difference in the occupations attended (DU38\&30). He gave further explanation:" women are more active in general, more anxious, more interactive, more commitment to attend than men are vary between very keen and not keen to learn, nothing in between"

It can be noticed from the obove informant that the trainee varied in their academic qualification but having the same job title. Also the informant R4 believed that, females were more committed to the training activitaies and attendance than male. The question has been posed to focus group too, they said:

"Most administrators programs include deputy directors and sometimes director themselves attend; different job title. And different experiences of course. Regarding qualifications some hold bachelor and some doctorates (DU150\&152)". They explained the years of experience: "...Between one to 20 years..."

From the perspective of trainer's, it is important to know if the trainees were aware of the training programme and whether they knew about the programme's objectives and themes before attending the programme. The fourth informant (R4) replied;

"... The biggest segment was medium (DU30)". He gives some examples for some different cases; "Some of the trainees attend the training programme after they have done some readings and search in the internet.....they have read my C.V. and some of the managers educations trainee they have average level and they don't participate effectively if you ask them they will answer and some other they attend the training programme without." 
It can be understood from the answer that the preparations of the trainees to attend the programme varied, and this in consistence with fifth informant (R5), he said:

"All attended and has the desire and interactive with the programme, but the disparity is there..... Attend late on the first day.... (DU $26 \&$ 32). He supported his view with that; Notes from some of the trainees that we received the call to attend late, and we wish we knew the themes in advance,... Change had taken place on the dates because of duplication between the activities in the provinces".

The six informant (R6) replay,

"General managers while attending the training they have kind of anticipation or apprehension. They have high expectation in the programme and they prefer a trainer to be old, with good position, Academy". He dig deeper by added some elabration;" they questioned whether the program going to added some knowledge to them really, because they have great experience".

It can be concluded from his answer that usually did not have much prior knowledge but merely anticipated some things from trainers. They preferred the trainers to have specific criteria that needed to be on the trainer as the following: high position, qualification doctorate and old in age. This can be interpreted as previously mentioned in research question 4. The reason behind is that the administrative trainers in Head training centre had not conducted any training for this category. AlHamuda (2012) found that the trainees did not see the themes and the aims of training programmes before they were conducted.

Gaps in trainee prior knowledge and expectations could be lessened if there is pre-program communication with the trainer. One of the most important components to success of training programmes is communication between the trainer and the trainees before the programme to make sure of the fact that the training objectives touch a real requirement as well as to determine the validity of the training objectives. Therefore, the researcher felt the need to make sure of the extent of the presence of a type of communication between the trainer and the trainees before conducting the programme. All trainers did not meet the trainees before the training. 
Informant (R4) and (R5) had replied respectively;

"Unfortunately, does not allow us to meet them... But we communicate with them through phone calls... (DU12\&13) and emphasis on the; I insisit the trainees to be communicating with me either through messages or phone calls...I send them some questions. (R5) said: did not happen at all. He gives further explanation; my concern.. sitting with all stakeholders and targeted group before the training but it never happened (DU16\&58)"

It can be observed that the trainers did not meet with the trainees but in some cases communicated with them through phone calls. In cases where there was prior contact, the gaps between the expectations of trainers and trainees were reduced.

\section{Contents of training Program}

The contents of the training program were given special attention. Owing to the religious and cultural background of the trainees, the contents of the program should include an attempt to integrate modern contents with Islamic beliefs and practices.

In the Islamic community, the perception of the individual about himself and his community plays an important role in his outlook whether it is either positive or negative towards himself and community. Each individual in a particular community is characterized from other individuals in a different community by a variety of features derived from the values that he believes in and that can be generated from Islamic education. The results of the existence of the Islamic educational values in construction profile for a Muslim it be in association with Allah Almighty, which makes him being watched Allah in secret and in public.

Muslims balance fear with the hope that Allah alone is the owner of decisions and fate, and it's all due to him. Thus, a Muslim who has the values of Islam is free from the fear of life, or fear for their livelihood, or fear from their prestige and status as life is in Allah's hands, there is not a creature's ability to diminish this life, an hour or a few hours:

"Say, Never will we be struck except by what Allah has decreed for us; He is our protector. And upon Allah let the believers rely". (Surat At-Tawbah, 51) 
The individual Muslim believes in Allah accompanied by mood optimistic which recognizes an individual with all the rights to life, asking him to seek self-assertion, which pays for the activity and work, and to seek the knowledge to understand the universe around him and define its role and function in the universe. This awareness is progressive with demanding change and reform for understanding and research, innovation and invention, and therefore man in the Islamic faith is vital. For the foregoing reasons, the researcher felt to introduce axis of values and development as part of the system with the effectiveness of training programmes.

The Omani Islamic society must play Islamic values role in building character of its member's Islamic humanitarian, so it should formulate divine touch in every home, to engage all in raising awareness of Allah as he has been commanded to raise and to have the guidance from Allah. The purpose of this question is that the researcher wanted to identify the extent of the presence of an emphasis on Islamic values in the training programmes and with what values; the question is considered as a prelude to the next question. The focus group said:

"It is not included all the time. Most of the trainers are Muslim and Arab. And mostly Arab.. commitment... cooperation, sincerity or honesty... (DU186 \&188)".

It can be noticed that there is no significant emphasis on Islamic values. Example of some Islamic values has been raised in training programme; Commitment, cooperation, honesty and sincerity. Informant (R4) replied;

"We use the method of delivering or
binding the values in the training program.
Motivating conscience means exciting hidden noble values
with the trainee....... (DU62). He gaves some examples;
"through creativity in motivating conscience...."

It can be concluded from his answer that the Islamic values have been emphasised by connecting the subject with the Quran, it helps attracting the trainees to the programme by emphasizing the moral side. All the informants 'supported the fact that raising the Islamic values through conducting training programmes helps to attract the trainees and motives them. 
Regarding the mechanism used to address Islamic values in training, the first informant (R1) and (R2) respectively said:

"Topics are all about skills gaining, in order to gain a skill, you need supportive sentimental side ...the trainer was focusing in giving supportive of this side by focuses upon the Islamic values (DU38). She enhanced his answer by some elaboration;" When there are debate in the training, the trainer always provide Religious aspects by this he was convincing people..."

"Has been integrated through activities through life situations, using a case study by some visual presentations in the video ... (DU54)"

It can be concluded from the above that the trainer gains trainees skills by stimulating the emotional side and tie it with religious values. The Islamic values are integrated with practical activities and linked with theoretical knowledge with examples from the Qur'an and Sunnah. The trainer perception about the method of integrated Islamic value in the training is not far from informants (R1\&R2) opinion, Islamic values from his perspective are linked to the Qur'an or Sunnah or the positions of the life of the Prophet's companions, either through raising the issue or through the implementation of operational activities. Moreover, values can be promoted through practical exercises. The trainees were attracted to the programme by emphasizing the moral side. Informants (R5) said:

"As we talked about the issue of the leader or head of the department is supposed to explore the possibilities and abilities of his employee... We discussed how the Prophet peace be upon him sees the Khalid bin Waleed that position in the field of Jihad.... Whether in the presentation or through the application.. (DU46) Human teacher peace be upon him say, I left you, with two things that you will not never go astray after me, the Book of Allah and Sunati .... Many of the administrative issues and many of the psychological theories and administrative fact that "our goods is return to us" there is no doubt that we dealt with this aspect".

All of the respondents agreed on the importance of including Islamic values in the training programs. These can integrate these values in several ways: to link the theoretical framework and cognitive side of the 
Qur'an and Sunnah, to give exercises or activities and link them with examples from either the Qur'an or Sunnah or the lives of the prophets Companions. Recent research in the field of administration proved that people who are doing to promote themselves through attention to the spiritual and moral side would be more competitive than their counterparts (Abdullah, 2012).

Ideally, the contents of the training programme should be reviewed and evaluated before running the programme whether in internal or external training. This is part of formative evaluation, an ongoing process that should accompany each stage of the training. The design of the training programme is one of the most important stages, so there should be some kind of pre-evaluation for programme work papers. Especially in light of the existence of standards, working papers had already been prepared and generalized to all directorates at the head quarter in $\mathrm{MoE}$ and educational general regions. The evaluation of work papers increases the quality of the training programme, which reflected on the increased efficiency. HRD is the department responsible of all training stages. Here, the focus group represented HRD. Therefore, the researcher asked this question to them, and they answered;

"...was supposed to evaluate the papers (including the hand-outs and worksheets) before the implementation of the programme for the internal training, however, but this was not committed by any department of the Ministry or the governorates ..... (DU 99 \& 101)". They give some justification that explains their failure to assess the work papers; "..When you ask the international experts to send you the content before the program they refuse."

Usually, organizers only ask for course descriptions goals and themes plus the curriculum vitae of the trainer. This means that the content of the programmes is not reviewed or evaluated. According to Azadgalah (2005) and Alloatie (2008), the content of training was repeated in spite of the different norms in addition to the lack of correlation between the content and contemporary thought.

\section{Organization and delivery of training: Setting, methods, and techniques}

How training is delivered is as important as the objectives and contents of the training program. This aspect includes the physical setting as well 
as the techniques, methods, audiovisual aids, and even the personality of the trainer.

Actually, in the Sultanate of Oman, in MoE, the training can be held in different places, but the researcher later wanted to know from informants' their opinions about the head training centre, the place that was belonging to MoE. Moreover, the researcher designed this question to identify whether the place was suitable or not, and if not she wanted to know how that could MoE develop the training head. The answers were obtained from trainees which were informants (R1, R2, R3) and trainer informant (R4) replied as follows:

"Head Training Centre (DU24)". (R2) gave the name of the place"....Nizwa College.....Emadist institute (DU32)". (R3) said" Was in external Hall.. he gave example In Sur Beach Hotel". (R4) mentioned" Hall not a training hall, main training centre". He gave the name of the hotel; "Zakher Moll”

Regarding training conducted in internal training centre, they meant head training centre or hired external premises hall in the hotel. The researcher believed on the importance of the environment in training as it was found by other researchers as one of the factors in determining effective training programme. The second informant (R2) said:

"For Mazoon College... Hall is a meeting hall and not training hall... Lecturer did not use certain sources that we can refer to it later.... service was good and available (DU34). She gave further explanation; Way of sitting was not are suitable ...there were no need to return to the sources of educational ... food and food facilities were available".

The informant thought that the place of training was not appropriate as well as educational resources while services were appropriate. From her point of view, there was no requirement to use external resources. The third informant (R3) mentioned:

"Suitable ... Hall is equipped to some extent (DU34)".

Informants gave different opinions; Hall was suitable and equipped. The informant (R4) agreed with informant (R3) as Halls were inappropriate, he repeated that twice. He said: 
“...Halls were not liable ... inappropriate (DU38 \&40)". Informant (R5) agreed with (R2) he said: In the governorate of Muscat, the hall was not prepared well, the level of nutrition was not appropriate. Of course.. tools generally available .... Sometimes the place is not suitable (DU38) he supported his idea with further explanation"...There were columns in the middle of the hall...... The lack of places for training in the Ministry of Education"

The informant's opinion was about training centres in general which were unprepared in terms of infrastructure. However, tools and devices were available. The informant thought that it would be ideal to add onto the head-training centre as another training environment in the MoE. Therefore the MoE needs to upgrade the infrastructure of the centre. Informants gave different opinions; (R2 and R5), talks of insufficient training hall and the need for improvement whereas the (R3) believed that the hall was good and enough. It might be because $\mathrm{R} 3$ received the training in five star hotels. For sure, the training environment was good.

Halls at the hotels are best in terms of capabilities and facilities, but the training centre either in the Ministry or in the educational general directorates needed to be upgrade in terms of number of halls, the capacity of training hall and the service while the facilities were sufficient. There are many reports within the MoE indicating that the training centres were not suitable and not enough to hold training programme planned by the MoE. According to Shayban (1995), there were deficiencies in the technical equipment for training and limited government agencies in the Sultanate, the agencies had enough equipment to a large extent (11\%) only, the proportion of the agencies that had the equipment to some extent $(50 \%)$ with the non-availability of these possibilities for the rest of the government agencies in the Sultanate. The data sample confirmed limited government agencies that are available with the devices and modern training aids $(11.1 \%)$ of the agencies, which are compared to its modern to some extent (47\%), and non-modern (27.8\%), and $11.1 \%$ did not have any devices at all. Recently MoE established "Specialist Center for Vocational Training for Teachers" to overcome the training programmes problems.

Regarding the length of the training programme, informants tried to explain the time of conducting training and the duration of the programme, the informants (R3) respondents; 


\begin{abstract}
"Choosing the time of implementation... were not a problem ... As a period... I think needs... to be longer. And elaborated his answered with" What gives us the reassurance that there were no problem in terms of execution time, because most of targeted people were able to be available"
\end{abstract}

It can be noticed that execution time for conducting training was suitable. However, the period for training was not sufficient. Informant (R2) had opposite opinion about suitability of duration and period of implementation, in her perception the duration of the two programs were enough and implementation time of the first programme was not appropriate. Because she was new as the head of section by that time. She was busy to understand her new job, and HRD selected her to attend the training programme. Thus, she was too busy handling her previous duties to substitute person. The head of the departments and her staff kept calling her; therefore her mind was disturbed between her new duties and the training programme. From her point of view, if the programme was delayed she would be more interactive with the training. She said:

“...Duration Was enough but timing was inappropriate ...
The second programme -technical leadership- was for one
week, duration was sufficient.... (DU38)". She gave further
elaboration" because we were recently designated as heads
of departments, we took the training session, and we have big
responsibilities and tasks ahead of us therefore we received
so many calls from the office"

Sometimes training programmes for educational managers included long set of objectives and themes while the training period was not exceeding two days in most programs, an average of 10 training hours. This led to the trainees to focus on the cognitive domain and neglecting skills and attitudes. There are many studies in the MoE and other ministries that revealed that effectiveness and quality of training do not have good impact on employees (Al- Hanashi, 2004 and Al-Qasimi, 2004). In this study, it was clear that there were many objectives that were needed to be covered in a short period of time and this also lead to in effectiveness of training on trainees.

Regarding the trainer's personality and performance, one of the informants (R2) commented that: 
"Their performance is good (DU16)". She explained and gave reason why their performance was good; "But there are better trainers than them.... I am.. and the group while discussing we viewed better trainers for this programme in order to improve the benefit of the programme...the trainers don't have to be from outside, we have Omanis expatriates in this field ..... However we shouldn't deny the positive impact on us..., gives us opportunities for discussion, acceptance of views and help us as trainees... But in the training methods lthey are closer to lecturers because they are academic lecturers than trainers"

The respondent answer indicated that trainer performance was good and the style of trainers was closer to the lecturers than to trainers. It means that trainer had used lecture method. The third informant (R3) replied:

"The trainer was terrific (DU22). He elaborated his answer with". Tried to affect the targeted group with Information and theoretical knowledge and evidence installer test and what came in the Qur'an and Sunnah.. .. He was trying to make change or lifting skills through the formation of conviction.... but... usually convictions that form as a result of the impact of knowledge is long or non-continuous".

Informant (R3) had a different opinion about the trainer's performance. This was due to the trainees that are from two different educational regional directorates each of them trained by a certain trainer. (R2) was trained by international trainer and had been working for a long time in the field of university teaching, so his performance tends to be a teacher more than a trainer. The second was the Omani trainer and had a long experience in the field of training. He is not from $\mathrm{MoE}$, but he is a training expert in one of the Civil Service Ministries. The lecture is the method most commonly used in training programs, and represents the largest percentage in the causes of the boredom of the trainees(AlTilbani et al.,2011). The same interview question had been conducted to the trainer. Informal (R5) said:

“...to a large extent and the evidence that Rating forms I received from the Ministry of Education of course they prepared the form Rating based on their goals, they also analysed these forms Rating form(DU24)" .He explained and gave reason why he said that "Thanks Allah... Some 
states reached 96 for the average each year, the least of 86 or 88. Therefore, it is an indication of success"

In general, we can conclude that most of the participants were satisfied with the presentation skills of the trainers. The finding was in line with that of Al-Masheke (2009), the results of his study proved the ability of trainers to prepare a lecture and display them in sequence with clarity, management discussions during lectures. The most important methods used in the training were lectures and workshops that relied on scientific material to provide trainees with them, the case study and the role play method was relied on them to some extent. The study of Al-Mashekee (2009) recommended having specific criteria's for the selection of the trainers which required experience and competence with them. There was need to train them effectively and provide them with all the competences necessary for the training process including: leadership ability, academic knowledge, good to deal with the group, a way to provide feedback, the ability to communicate, influence and persuasion

As regards the techniques and aids used during the training programme, respondent (R1) had an interesting point of view: "No need for the trainer to use sophisticated technology...he used PowerPoint and direct speech...he obtained the objectives (DU18)"'

From her point of view the trainer used simple techniques and achieved the objectives. The finding was related to that of Al-Mashekee (2009) where the most important teaching aids used were computers and modern technologies associated with it and others included were overhead projector, the blackboard, drawings, maps, illustrations, reference books, periodicals, pamphlets (printed materials) and movies (audio visual aids).The second informant (R2) said: “... The only means used were (Data show) for illustration display. The way they sit on the horseshoe-shaped.. did not allow discussions and group activities (DU18)".

The answers were different with her opinions about the adequate of resources in various ways. There was inadequacy of the means used. Trainees sat on the horseshoe. This finding is not consistent with previous informant (R1) and that of A1-Mashekee (2009) which could be because the study evaluated all programmes and policies, training of human resources from the perspective of total quality management applicable to Educational General Directorate- (Dhofar - Oman ). It evaluated all 
the training programmes conducted in Educational General Directorate - (Dhofar - Oman), so the results were consistent with the results shown in the Annual report of the professional development for the year 2010, 2011 and 2012. In addition, informant (R1) attended programmes with another trainer where the method had different and training aids. The current trainee from the governorate of Muscat talked about training aids that were used in the two programmes, which he attended.

\section{Outcomes of training program}

Training would be useless if it does not lead to change of behavior or attitudes among the trainees. This theme discusses respondents' perceptions of the benefits of training programs in terms of whether they actually applied the new knowledge and skills acquired. Respondents (R1\& R3) stated that they gained skills and knowledge from the exchange of experiences among the trainees which has been applied and their replays were as follows respectively;

"Yes... for (ROI)..... other programme was ... foundational helped us in giving us some evaluation, that can be used to measure our performance,... we entered into how to deal with staff .... . The exchange of experiences was the most useful thing in this programme (DU44). The programme was in two-part theoretical and practical. (R3) said: I applied the values ... when I start forming team work, this team work should be specialized...team work must have a leader capable of managing it well... and capable of distributing missions... how to integrate each other,... these roles in the end serve to the benefit of the work ...(DU50)"

The views of Informants (R7 \& R8) were close to each other as their answers had some similarity with informants (R1 \& R3), as follows;

"Yes (DU17 \&19)". He gave further explanation; the programme, which we took must be re-posed to others on the basis of what presented and we benefited from it ... we use to follow a particular pattern in the administrative work after attending this programme we .. supposed to be better". ( R8) said :"Usually yes ..(DU14)". She support her answer with; "they refer to the information and notes taken during the training programme". 
From their answer, we can conclude that there was some sort of practice of the learning skills in the workplace with different contribution levels. On the important topic of change in behavior, the first informant (R1) said:

".. Administrative and technical skills.. little changes .. 2 out of 5 degree, but in the (ROI) programme..out of 5 degree ..I can say 4.5.. the technical program the changes was fixed ..(DU46)"

It can be seen through her answer that the administrative and technical skills have lesser impact whereas the programme (ROI) has high impact. It is acceptable because the first programme was not based on the desire of the trainees as it was not built on a real need while the second programme was at the heart of the work of the trainee in addition to her department which was the request for, planning and organizing of the programme.the answer of Informant (R3) was different from (R1), he said; "Not that much (DU52\&54)".

It is apparent that the programme contributed slightly to the change of trainees' behaviour. Based on the trainees' answers, there were different impacts in their behavioural changes. The same question had been asked to the boss and the subordinate of the trainee and their (R7, R8) answers were as follows respectively;

"Contributed a lot.. (DU34). He gives further explanation; "Subjecting the individual to new information ... or a particular position or a particular exercise for sure be positive to work... Our practices that may be ... spontaneous... after the training ... it was standardized scientifically". (R8) said: "contributed to some extent, it begins to contribute to the change and development of the participants (DU38)". She supported her answer with;" some guidance for senior supervisors on how to solve the problems and reduce the load of problems which exist in the field"

It can be revealed from the above responses that training contributed to a change in behaviour, which reflected positively on the educational training programmes. So positive behavioural could change to standard practices and skills. It is apparent that human being daily learns a lot of knowledge and experiences many based on practices while of them are not practice in everyday life, they will not gain. Researcher designed 
this question to identify the extent to which it offers the knowledge and experience to acquire from programmes. The informants (R1 \&R2) answered respectively as follows;

"The technical programme was fixed (DU48)". She comments on the secound programme and she gaves further explantion;" the aim was to establish the right mechanism of action and based on the scientific basis for the department ... This achieved... and now we follow this system ..." (R2) said:"...Most or all of these skills I have them....(DU62). She support her opinion; by the team does not, but I noticed my rating through my employee through my sense of their satisfaction while dealings I feel the program has achieved the objectives thankfully".

Informant (R9), a senior administrative supervisor, had this to say: "He has a broad knowledge, and he benefit from the experiences of others and also he follow what he believes in (DU38)". This somehow implied that trainees practice the skills acquired continuously. While there was variation in the responses among the informants, we can observe some sort of agreement that there was some kind of observed change in working behaviour in addition to a type of consistency in some acquired behaviour from knowledge and experiences gained from training programmes and trainees opinions were supported by with their employees and their managers. The finding of the related study conducted by previous researchers (Al-Kaabi, 2002; Sangoor, 1997; Shayban, 1995) confirmed on the lack of an association between training needs and design programmes, where there was no measure of training needs in accordance with the curriculum of modern scientific needs. This latter was offered in training halls which was not associated with reality that focuses on information and theories.

Ideally, there should be assessment of the cognitive level, and at the application level after the trainees return to their workplace. On this point, the first informant (R1) said:

"There was learning evaluation, pre and post evaluation ...for the administrative and technical skill programme there was no evaluation....Professional Training plane covers only $1 \%$ of the programs and ROI is carried out accordingly.... The percentage of evaluation of programs at each level varies... 
evaluation of interaction and satisfaction supposed to cover $90-100 \%$ of the programs in learning the same thing 90 $100 \%$ of the programmes in the application level I think 40 $50 \%$ and the evaluation decreasing till reaching $1 \%$ (DU56, $58 \& 60$ ). She explained her answered by some example;" The average of pre-evaluation was 1.5 to $2 \%$ from 5 post evaluation became $3.5-4 \%$ this was in learning skills.... a clear plan for the program at every stage from $\mathrm{A}$ to $\mathrm{Z}$ till the measure of impact and then plan application for a trainee ... and how it claimed to be measuring instruments."

A study by Al-Adawiya (2009) indicated that the process of evaluating training in training centres in $\mathrm{MoE}$, was not convergence with proper attention to be activated and that the most as the tools used to evaluate the training programme was a questionnaire, which was different from one centre to another. There was no organizational structure of the evaluation process, there was no a procedural manual nor the team specialist in evaluation, as it did not take place within the scientific basis for the evaluation of the planning, execution, analysis, judgment and follow-up. As there were no reports of the evaluation, but there was a report of training which contained training programmes carried out by the Centre in the financial year with the objectives, target group, the kind of the program, place of execution and data about the trainer and the training centre.

\section{Evaluation of training program}

The final theme is about the overall assessment of the effectiveness of the programmes and whether there are inbuilt procedures for evaluating the program. One of the components of a successful training programme is the clarity of the objectives and an assessment of the extent to which they have been achieved. Regarding this, informant (R3) said: "The level of knowledge and the level of conviction of the importance of teamwork might have been achieved (DU28)'. It can be noticed from this respondent that the programme's objectives were achieved on the level of knowledge and teamwork only. This finding is consistant with Al-Hanshi (2004) on the civil service,where in it was concluded that training programmes were not effective and had shortage of quality, for instance, the training programme was not targeted all job categories and the weakness in training was of not helping to improve employees skills, lack of quality in all training process stages. There was a lack of 
objectivity in the nomination or selection of trainees to attend training programmes. In another study conducted on identifying training needs and their impact on the development of performance in the Ministry of Awqaf and Religious Affairs, it has been found that the training did not meet the objectives in all dimensions i.e. cognitive achievement, skill development and simulate the attitude (Al-Qasmi, 2004). According to informant (R3) the programme achieved parts of its objectives. Informant (R2) said:

"Administrative and technical skills Development
Programme achieved the desired objectives at a higher rate
than the other programme ... Leadership programme was a
for one week, did not add new thing to me, while the other
skills development programme administrative and technical
might be a little better (DU30). She gave further explanation;
The second programme the art of leadership, Lecturer was
Arabic, but holds citizenship of European.. way of delivering
information was truncated "unsuitable"

Informant (R2) compared between the two programmes attended while she was of a head section; the first programme administrative and technical skills Development- this program achieved the desired objectives at a higher rate than the other programme - The Art of Leadership- where the programme did not add any information to the trainees. However, the Informant (R2) did not go for any further explanation as how the objectives had been met.

To what extent do the training programmes have inbuilt evaluation mechanisms? Considering that the government is spending large amounts of money on staff training, it is imperative to assess the impact of training programs on the participants. On this point, the first informant (R1) said:

"Was evaluated and the results of the theoretical evaluation were $90 \%$... and for managerial and professional skills were not evaluated ... Evaluation was done at the end of the program by questioner and the presence of evaluation specialist... (D56)". She explained her answered by some elaboration; "If the duration of the programme is two weeks, the evaluator needed to attend two sessions ... taking note and recorded in special forms. .. notes on Trainer on the trainee's, training material and services provided to 
the auditorium and problems .. if any problem he tells the coordinator of the implementing agency of the program to find solutions".

It noticeable here that the method of evaluating and assessment tools for the two programmes varied as pre-evaluation and assessing at the end of the programme for the second programme while no any evaluation for the first programme. Informant's (R2) response reflected that there were no follow-up on training effect. She said: "We were not been evaluated .... What we have gained from the experience of leadership or of managerial experience, nor the return investment of the impact of the follow-up training (DU50)".

The trainer did not assess trainee either during conducting of training programme or after the training. Note that the trainer is the most capable and competent in measuring the extent to which the objective, because the training material was prepared and presented by him. The fourth informant (R4) said: "No..they evaluate..mostly in the end of the training program (DU54,58 \&65)". He gives further elbration;" In the training programme people from evaluation of train investment distribute questioner for evaluation".

According to the study conducted by Al-Alawi, (2003) to evaluate whether the training programmes in Oman at the training institutions are evaluated, he revealed that the majority of the training institutions and the government organisation in Oman using different methods of evaluation during the programmes implementation or at the end of the training programme and there was no follow up on trainees performance after the training programme. In another study conducted in $\mathrm{MoE}$, by Al-Hsani (2012), it is clearly found from the statistical analysis that evaluation of training and determining training needs ranked least importance in the effectiveness of educational training centres. AlMashekee (2009) in his study concluded the importance of evaluation of training programme by natural bodies to see whether the amount spent is equivalent to the return of training on human development. This research also emphasises the importance of the evaluation of the training programmes by the trainers, organizing agency and the department of Evaluating Training Impact at all level of training programmes.

On overall perception of effectiveness of training, the first informant said: 
"The administrative Programmes for heads of section or heads of departments are not based on real needs (DU50)". She supported her view with that; "For administrative programmes either trainers propose the training materials or trainees ask for it.. Training programmes provided are often have no clear strategy which they are required after that ... Where are the strategies ... how the trainee can deal with it ..the focus was always on the planning, and no attention was given to the implementation and evaluation of the programme."

The informants emphasized on the administrative programmes, which were not based on a real needs, she repeated this statement four times, which reflected that she felt it as reality. This indicated the major problem and the reason behind the failure of training programmes. The second informants ( $\mathrm{R} 2$ ) replay;

".....Working to increase the quality and increase the efficiency or improve and thus raise the level of productivity (DU64)". In addition, she emphasis on"... The trainees who been with me were from heads of transportation departments, heads of other departments they did not attend any training programme before and have no idea how to deal with their staff?"

The second informant (R2) slightly differed by arguing that the programmes increased efficiency and quality for those who never attended any training programme before. On the other hand, she looked at the programmes for those who had experience it is not effective. It seemed that from perspective of both $\mathrm{R} 1 \& \mathrm{R} 2$, programmes not effective. Informants (R5) who is trainer and Omani said:

"There is evoluation and precisely what they are doing now to measure the impact of the training... mechanisms and objectives of the Form changed thus really improved and increased the training efficiency...... I noticed that unfortunately.. I do not specify any departments, but in some departments an individual cases using the characterization from another place and presented as their training needs for their employees, but this cannot be generalized......... Of course, there is improvement in the training evaluation 
(DU50)". " He elaborated his answered with some example such as; "Now measure the impact of training .. means to increase efficiency and quality, now pay attention to the issue of quality and the issue of training"

We can observe that whereas there evaluation was conducted on the training programmes, sometimes the programmes did not match the actual needs of the trainees. Training is often not based on real needs. Thus starting measuring the impact of training programmes, in the Ministry of Education, as an indicator of increased efficiency and quality. Therefore, there is a kind of some improvement. It is in consistence with the previous study of Holt (2011) about creating effective leadership development programmes for a descriptive quantitative case. The result indicated that the effective training programme should focus on focused individual needs; their needs were different according on their responsibility, the enhancement of teamwork, employee motivation skills \& communication skills. Moreover, the study proved direct connection between training and developing core competencies. The different kinds of training like formal training, informal training and on the job training helped in developing project management.

Satisfaction with project management services is essential for doing their role. On the other hand, the results of studies confirmed that some training programmes were promising in spite of some weaknesses which needed to be improved in order to enhance their effectiveness. The effective training programme should focus on individual needs like responsibility, enhancement of teamwork, and communication skills, despite no specific evaluation scheme can match all excepted needs. Informant (R8) raised another issue she said: "Since I become a Director of the Department, I have not attended any training programme... not gone through any training programme ..... I think for my case the chance of training is very limited (DU44)".

This is important since this respondent is a director of one of the most important departments in one of educational general directorate and she is a supervisor of one of the trainees. The fact that she did not attend any training programme reflects the unfair distribution of training opportunity. Apparently there were limited or no programmes for people at this level. 
Finally, the overall impression about the effectiveness of the training programmes in terms of evaluation tools, self-evaluation, assessment of trainees, and peer evaluation, the third informant (R3) said:

"We have a special training package for school principals and school supervisors. The training packages for the new supervisors does not actually touch the real need as it happen with In Our schools, the training Package for the school principals and assistants is imported and MOE translated it, where many of the existing things are not ...related to the technical side.. We need training packages related to us that discuss our problems and discussed our real needs... (DU62)".

Notes from answering indicated that there were weaknesses of training packages in the Ministry, and were not touching the reality of the work. The fourth informant (R4) and seventh (R7) approximately were had similar answers as:

"Above average... the availability of infrastructure with a
more keen of educational leaders... (DU74)". Informant (R8)
reply; "Programs are of an average level (DU50)". She gave
example that means, "Some programs were excellent and
some programmes were weak, so we took the average"

Most of the respondents rated the training programmes in $\mathrm{MoE}$ to be above average level despite the availability of financial resources and educational leaders who are keen on the development. In their point of view MoE has good leaders, they sought to qualify of the training with the availability of high budget but still the level of the training programmes fell between excellent and weak. According to Al-Khalili (2002), his research was carried out on evaluation of training for Omani civilian employees to explore and evaluate the impact of existing training programmes on employees in civil service units. The study found that the existing training programs werer promising. Although there were some weaknesses in these programmes which needed to be improved in order to enhance the effectiveness. The study suggested that to overcome the highlighted challenges, there is need for support from the top managers in civil service in terms of improving the training programmes. 


\section{CONCLUSIONS AND RECOMMENDATIONS}

The study revealed that all of the respondents agree that the training programmes are not built upon real needs, as such the trainings do not have much impact on trainees and training quality have some problems. Based on the findings of this study, it is recommended that, the training specialists need updating with new skills and knowledge related to their specific field and training, in general. These trainings should be from various resources and can be internal or external. Moreover, the training specialists need to practise their skills and knowledge which will help them to develop. There is need to prepare specific criteria for the selection of qualified trainers with experience, qualifications and skills training. Trainers can be developed through exchanging visits, attending a conference such as Global Training STD, and exposing the trainers to other training schools like the Japanese, Korean and Malaysian. There is need to make learning language other than Arabic as mandatory for each trainer. There is also a need to provide opportunities for them to implement training programmes, according to their specialty. Diversifying the sources of training, such as increase training tools, remote training and the provision of sites for trainers on YouTube are necessary to expose them to an on-going programmes. Each phase of training of trainers (TOT) should focus on improving specific competency. Permitting Omani female trainers could be pioneer in this field. The trainers need to have opportunity to meet trainees and listen to their needs of self-assessment, and deal with the training as a mission but not as carrier. There is also a need to enhance finance committee with specialised training for an event management. Training programmes for educational managers should be based on the level of competency they possess. There is need to mix the educational managers in the headquarter ministry with their counterparts in educational regional directorates in some of the programmes, taking into account to also separate them in some programmes to distinguish between the managers who work in the headquarter ministry as supervisors to the rest of the managers on the educational regional directorates. Benefit from "educational managers competencies" (EDUMAC) model may be received from the study to serve as a Road Map of the building and facilitating training programmes for educational category managers. There is need to prepare different training packages that suit each level of educational manager. The Training Policy needs to improve in line 
with the new training dimension. Linking the training track with career path has to be associated with functional upgrades for completion of certain training packages. This increases the motivation of trainees to attend training programmes and it will be the reward for them. The training programmes should also take into consideration organisation's requirement. Leader or educational manager need to be with vision and mission with high technical administrative skills among managers as the training programmes need to focus to diversifying the training objectives such as cognitive, skill and attitudes. With the need to build programmes on the value aspect, the emphasis on the presence of clear formats through the ministry and accurate follow-up by the concerned has to be made to develop conceptual skills. There is also a need for diversification of techniques and training methods to include remote training provides more flexibility for trainees, with more emphasis with new practical approaches to enhance this competency. Adoption of a strong evaluation system is needed so that it can assess the training process in all its stages starting from the identification of needs and then planning including the objectives and content, through implementation of the first training sessions, assessing the level of satisfaction to the end of the assessment of return on investment, whenever it is necessary. The participation of trainer is required in evaluation especially at learning and practicing level. There is a need for outsourcing the use of external experts to evaluate the training to give an impartial and objective judgment on the results of training make sure that the return of training is equivalent or weak in spending. Moreover, it involves the department of evaluating training impacts with them to give them an opportunity to gain experience. The issuance of a unified procedural manual for the evaluation process explaining the basis for the evaluation and followup mechanism has been practical with the inclusion of the theoretical framework adopted by the ministry in the evaluation, including the assessment tools that deal with the various phases of training, characterised by reliability to produce consistent and valid results. Training all stakeholders is required on the unified procedural manual in the two level headquarter and educational regional directorates. Activating publication of the annual reports of the professional development is for the betterment of the training plans from where useful feedback is provided for future planning and policy formulation. It is needed to prepare a data base of trainees and training programmes, including information on the results. Distribution of evaluation papers 
among MoE employee in general and educational mangers specifically is required. This can be achieved by different methods for instance during the formal and informal meeting, brochures, Conferences and seminars. The training plan needs to be based on the accurate training analysis. The ministry needs to adopt new method that match with the number of staff in MoE, in different fields, job title and responsibilities. There are different types of analyses to examine human capital needs the organization analysis, Job analysis and Individual need. There is need to prepare a long-term plan, which considers all $\mathrm{MoE}$ needs and all factors, postings of all individuals involved (target group, educational directors, actors requesting programs, decision-makers) which will help to get successful training programmes. The educational manager and HRD may collaborate and play crucial role in this plan and proper clear training system for selecting employees to attend training programmes, Furthermore, for the nomination of who will attend the qualification courses, clear system and procedures are needed. In addition, it is helpful to include clear job descriptions system to help manager and HRD for selection and the trainees feel satisfied. There is need to exchange experience and collaboration between managers among civil service units and private sectors. While implementing the training plan, it is necessary to take into consideration, the suitable duration time of training programmes to the trainees, the right trainer for the topic, the appropriate methods or approaches and different aids. MoE needs to change the head-training centre and based on researcher knowledge they can shift the head-training centre to another location, which is new and smaller than the previous. The training centre requires providing quite number of wide training halls, new facilities, training aids and resources.

\section{REFERENCES}

Adawiya, N. M. S. (2009). Reality Training Calendar Training Centers in the Areas of Educational Foundations in the Light of the Process of Evaluating the Sultanate of Oman (Unpublished Master's Thesis), SQU, Sultanate of Oman.

Al-Alawi, K. S. (2003). The Evaluation of Administrative Training in Training Institution in the Sultanate of Oman ( $\mathrm{PhD}$ thesis , Institute for Development Policy and Management (IDPM), University of Manchester, Manchester). 
Al-Hamuda, S. H. A. (2012). Developing Training Competencies at the Diwan of Royal Court in the Sultanate Of Oman. MBA, Caerdiff Metropolitan University Prifysgol Fetropolitan Caerdydd, UK.

Al-Hanashi, M. A. (2004). An Investigation into Quality of Training on Civil Service Units in the Sultanate of Oman. Sheffield Hallam University; School of Business and Finance.

Al-Kaabi, S. R. (2002). The Impact of Training on the Development of Regional Administration: Application to the Ministry of Internal Affairs in the Sultanate of Oman. (Unpublished Master's Thesis). Cairo: AL-Sadat Academy for Administration Science.

Al-Khalili, S. (2003). Evaluation of Training for Omani Civilian Employee (Unpublished master's dissertation). University of Leicester, Leicester.

Al-Mashekee, S. (2009). Evaluation of programmes and Policies, Training of Human Resources from the Perspective of Total Quality Management Application to the Directorate-General for Education (Dhofar - Oman). Arab Academy for Science, Technology, and Maritime Transport Institute of Productivity and Quality

AL-Qasimi, S. N. (2004). The Needs Analysis and its Impact on the Performance of Development. (Unpublished Master's Thesis). Cairo: ALSadat Academy for Administration Science.

Al-Rawas, N. B. M. B. A. (2011). The Directrate Genral Of Humen Resources Development (Oriention Booklet) (first ed.). Ministry Of Education.

Annual Report of the Professional Development for the Year. (2010). The Directorate General for Human Resources Development, www.moe.gov. om.

Boverie, P., Sanchez, M. D., \& Zondle, J.A. (1994). Evaluating the Effectiveness of Training Programmemes. Retrieved from http:/ /hale.pepperdine.edu/ $\sim$ cscunha/Pages/ KIRK.HTM.

BTI, B. S. S. I. (2012). Oman Country Report. Retrieved from http://www.btiproject.org website.

Creswell \& Plano Clark (2011). Designing and Conducting Mixed Methods Research. Thousand Oaks, CA: Sage Publications, Inc.

Creswell, J. W. (2008). Educational Research: Planning, Conducting, and Evaluating Quantitative and Qualitative Research (3rd ed.). Upper Saddle Creek, NJ: Pearson Education. 
Croes, S. (2012). Kirkpatrick's Four Levels of Evolution. Retrieved from http:// www.mastermind-ink.com

Gall, M., Borg, W., \& Gall, J. (1996). Educational Research: An Introduction ( $6^{\text {th }}$ Edn.). New York: Longman.

Garavan, T., N, O'Cinneide, B. (1994) "Entrepreneurship Education and Training Programmes: : A Review and Evaluation - Part 1. Journal of European Industrial Training, 18(8), 3 - 12

Guskey, T, R. (2000). Evaluating Professional Development. Thaousand okas, CA: Corwin Press.

Holt, S, W. (2011). Creating Effective Leadership Development Programs a Descriptive Quantitative Case. Unpublished Dissertation, University of Navada.

Holton, E. F., Bates, R. A., \& Ruona, W. E, A. (2000). Development of a Generalized Learning Transfer System Inventory. Human Resource Development Quarterly, 11(4), 333-360. http://portal.unesco.org/en/ ev.php

Holy Quran. Retrieved from http://www.ahl-alquran.com.

HRD. (2010). Annual Report of the Professional Development for the Year. The Directorate-General for Human Resources Development, MoE. www. moe.gov.om.

HRD. (2011). Annual Report of the Professional Development for the Year. The Directorate-General for Human Resources Development, MoE. www. moe.gov.om.

HRD. (2012). Annual Report of the Professional Development for the Year. The Directorate-General for Human Resources Development, MoE. www. moe.gov.om.

Kirkpatrick, D. L. (n.d). Implementing Kirkpatrick's Four Levels. Retrieved on 13 December, 2012; from http:// astd2007.astd. org/ PDFs/ Handouts\%20 for $\% 20$ Web / Handouts\%20Secued\%20for\%20Web\%205-15\%20 thru\%205-16/ TU101.pdf

Kirkpatrick, D. L., \& Kirkpatrick, J. D. (2007). Implementing the Four Levels: A Practical Guide for Effective Evaluation of Training Programmes. San Francisco: Barrett Koehelr.

Mininstry of Education. (2012). The Annual Educational Statistics Book (2 Edn.). Sultanate of Oman: Ministry of Education. 
Ministry of Higher Education. (2012). http://www.virtualcampuses.eu/index. php/Oman.

Ministry of Information. (2013). http: //www.omanet.om/English/hmsq/ hmsq12.asp1.7, retrieved on 8/4/2013.

Sangoor, S. H. (1997). The Planning of Human Work Force in the Civil Service Sector in the Sultanate of Oman. (Unpublished Master's Thesis). Cairo: College of Trade.

Shayban, U. S. (1995). Using of Human Work Force in Public Organisations and its Problems. The Administration Journal (54). 